\title{
Suspected poisoning in children
}

\section{Study of the incidence of true poisoning and poisoning scare in a defined population in North East Bristol}

\author{
M. W. CALNAN, J. W. DALE, AND C. P. de FONSEKA \\ From Medical Research Division, Health Education Council, Bristol
}

\begin{abstract}
Calnan, M. W., Dale, J. W., and de Fonseka, C. P. (1976). Archives of Disease in Childhood, 51, 180. Suspected poisoning in children: study of the incidence of true poisoning and poisoning scare in a defined population in North East Bristol. The distinction between true and suspected poisoning in children has not been made clear in previous work on childhood poisoning. A study of suspected poisoning in children under 15 years of age in a defined population of North East Bristol from November 1970 to July 1973 carried out by the Health Education Council Medical Research Division included 53000 child-years at risk. The number of suspected poisonings was $3 \cdot 4 / 1000$ population aged under 15 years per year, with a higher incidence in younger age groups.

Detailed investigation of the circumstances of the accidents carried out by a multidisciplinary team showed that at least $65 \%$, and possibly as many as $78 \%$, were poisoning scares and not true poisoning. The evidence used by the casualty doctor and by the parents to diagnose poisoning was explored, and in many cases was circumstantial. Children with fathers in nonmanual occupations were over-represented. This may reflect differences in patterns of utilization behaviour rather than true differences in incidence.
\end{abstract}

The distinction between true and suspected poisoning is not made in clinical and epidemiological published reports. The adult who requests treatment for childhood poisoning may suspect that the child has taken something dangerous but is not always certain. Often the substance has not been taken, or too little has been taken to hurt, or it has been spat out, or removed by someone before it was swallowed. Thése are instances of 'poisoning scares', distinct from 'true poisoning' in which an ingested substance either produces undesirable symptoms whether temporary or permanent or where prompt medical treatment averts the development of symptoms. For clinical and epidemiological purposes we should count all such children brought to medical care services as cases of suspected poisoning.

The only nationally available statistics, the Hospital In-patient Enquiry (HIPE), cover children who spend one or more nights in hospital and do not distinguish between poisoning scares and true

Received 28 May 1975. poisoning. There are no available statistics on children taken to a general practitioner, or to a hospital emergency department; and there is no way in which to gauge the number of children who develop symptoms but are not examined professionally.

In this study we have examined the validity of these national statistics, explored the concept of poisoning scares, and considered relations between objective evidence of poisoning, diagnosis, and treatment. Field studies of accidental poisoning in children have been carried out in the United Kingdom by McKendrick (1960), Carter and Wilkinson (1966), and Jackson, Walker, and Wynne (1968). The authors have recommended several preventive measures, the relevance of which we examine in the light of our evidence.

\section{Methods}

This study is part of a general study of home accidents in North East Bristol undertaken by the Medical Research Division of the Health Education Council from 
November 1970 to July 1973. The general study population consisted of 127000 residents in a defined area of North East Bristol which in age, sex, and social class composition is close to that of England and Wales as a whole. All events which involved medical care services were investigated by members of the division (de Fonseka and Roberts, 1972).

In our study of child poisoning we monitored for 119 weeks the population of 23457 children aged under 15 years living in North East Bristol. Hence there are 53000 person-years at risk. All children who used medical care services in the area because of suspected poisoning were visited within a few days of the incident in the course of the general home accidents study. The authors later studied nearly all cases in depth. The substances and containers were examined on site and the adult who was at the scene was interviewed where possible. Hospital records were scrutinized for data on diagnosis, treatment, and presence or development of symptoms.

178 episodes of suspected poisoning were notified in the study. 2 children were involved in five episodes, that is a total of 183 children. In the cases studied medicines, drugs, household products, and natural substances were involved but suspected poisonings from gases and vapours were intentionally excluded. The response rate in the general study was $95 \%$ and for the in-depth study $91 \%$. In all 183 cases the age and sex of the child and the type of substance were known.

\section{Results}

Incidence. The incidence of suspected poisoning which resulted in medical care was $3 \cdot 4 / 1000$ population aged under 15 years per year; $8 \cdot 7 / 1000$ aged under 5 per year, compared with an incidence of $0 \cdot 5 / 1000$ population for the group aged over 5 and under 15 years per year. There were more males than females in the sample but the difference was not significant.

True poisoning and poisoning scares. In Table I the suspected poisoning cases are divided into poisoning scares and true poisonings. The most striking finding was that only $22 \%$ of the children developed symptoms of poisoning such as spontaneous vomiting or diarrhoea, extreme drowsiness or dizziness, burns, collapse and coma, as well as other signs including pneumonia. In another $13 \%$ of cases, though there was objective evidence that the child took a toxic substance, no symptoms developed. At least $65 \%$ (118 cases) were cases of poisoning scares and the remainder will be treated as true poisoning. However, the figure for poisoning scares may be as high as $78 \%$, thus forming a substantial proportion of cases of suspected poisoning.

\section{TABLE I}

Distribution of persons under 15 years of age seeking medical care after suspected poisoning. Evidence of poisoning was by presence and severity of symptoms

\begin{tabular}{l|r}
\hline & $\%$ \\
\hline Poisoning scare & 65 \\
(a) Child did not take substance & \\
(b) Child took innocuous substance or innocuous & \\
amount & \\
True poisoning & \\
(a) Clinical evidence that child took substance, & 13 \\
no symptoms & 21 \\
(b) Symptoms of poisoning present & 1 \\
\hline Total (n=178 $)$ & 100 \\
\hline
\end{tabular}

^Hospital notes were not available in 5 cases.

Evidence of poisoning in casualty. The relation between initial diagnosis by the casualty doctor and objective evidence of poisoning was examined (see Table II). The doctors correctly detected $85 \%$ of true poisoning cases, missing $15 \%$. However, they diagnosed $68 \%$ of the poisoning scares as having ingested toxic substances. Casualty doctors may consider that they have insufficient evidence to rule out true poisoning and must therefore play it safe. But once made aware of the strong probability of poisoning scares, casualty doctors may be led to take more careful histories, and, in addition, better diagnostic facilities may be developed for use in casualty. A short observation period in casualty may be instituted before the expensive, emotionally taxing, and often unnecessary treatment is begun. The use of emetics might also reduce the need for admission (Goulding, 1971; Meadow and Smithells, 1971).

Evidence of poisoning in the home. In order for parents to believe that a child requires medical care for poisoning, either symptoms of poisoning must be evident or the parent must suspect that ingestion of a toxic substance has occurred. We examined what evidence parents used to decide that poisoning had occurred.

The strongest evidence of poisoning available to the parent are signs of symptoms in the child. These may be specific, such as vomiting, exceptional drowsiness, collapse, coma, or less frequently convulsion. In our study $17 \%$ of the cases showed specific symptoms. However, the signs or symtoms may not be strong enough to suggest that the child has been 'poisoned' but may only indicate that something is wrong, e.g. choking, coughing, screaming, or refusal to eat. $12 \%$ of the cases fell into 
TABLE II

Doctor's initial diagnosis of suspected poisoning, and evidence of true poisoning and poisoning scares for persons under 15 years of age seeking medical care

\begin{tabular}{|c|c|c|c|c|c|c|}
\hline \multirow{2}{*}{ Doctor's initial diagnosis } & \multicolumn{2}{|c|}{ True poisoningt } & \multicolumn{2}{|c|}{ Poisoning scare } & \multicolumn{2}{|c|}{ Total } \\
\hline & No. & $\%$ & No. & $\%$ & No. & $\%$ \\
\hline $\begin{array}{l}\text { Ingested toxic substance* } \\
\text { Ingested no toxic substance }\end{array}$ & $\begin{array}{r}51 \\
9\end{array}$ & $\begin{array}{l}85 \\
15\end{array}$ & $\begin{array}{l}80 \\
38\end{array}$ & $\begin{array}{l}68 \\
32\end{array}$ & $\begin{array}{r}131 \\
47\end{array}$ & $\begin{array}{l}74 \\
26\end{array}$ \\
\hline Total & 60 & 100 & 118 & 100 & $178 \ddagger$ & 100 \\
\hline
\end{tabular}

*Includes all children treated or admitted to hospital for one night or more.

tIncludes all children showing symptoms of poisoning or clinical evidence of having ingested a toxic substance.

¥In 5 cases the necessary information was not recorded in the hospital notes.

this group, and these two case groups include all cases where there was some direct evidence of poisoning.

We next examined the evidence used by the parent that ingestion had occurred though the evidence of poisoning was not so clear. Sometimes a parent inadvertently gave the substance himself ( $1 \%$ of all cases). Sometimes there was visual evidence of a foreign substance on or around the mouth, a smell in the exhaled breath, or the parent had seen the child put the substance to or in his mouth (33\% of the cases). This and the previous evidence confirms that the child has had the substance in or round his mouth, but does not of itself constitute evidence of ingestion. The bitter and unpleasant taste of many substances causes children to spit them out. A report by another child may be used by the parent (15\% of the cases). Finally, the evidence may be entirely circumstantial. The parent may have no evidence of ingestion or even that the child has put the substance to his mouth, but he thinks a quantity of the substance is missing and is frightened ( $22 \%$ of the cases).

Thus parents use a variety of evidence to judge whether or not their child has ingested something. What evidence do they use to decide that it is toxic?
It is only the adult at the scene of the accident who is able to decide whether or not the substance is toxic and treatment is therefore required; or if he is uncertain of the toxicity whether advice is required; or if he is sure the substance is nontoxic that no action is required. Since in the last case the child will not then be brought for medical care, we have no evidence about this situation in our present study. However, we did inquire as to the adult's belief about toxicitiy and compared this with the true toxicity of the substance, graded into three groups (see Table III).

The National Poisons Information Centre provided information on toxicity, which was graded with acute rather than chronic poisoning in mind. Substances defined as innocuous are innocuous in acute dose; those substances defined as occasionally dangerous would seldom cause serious disorders when taken in acute dose; and those substances defined as toxic would cause serious disorders in acute dose.

In just under half the cases the parents were in doubt whether the substance was toxic or not, the most uncertainty occurring among substances that were classified as innocuous and the least among substances that were toxic. The evidence of in-

TABLE III

Beliefs of parents about toxicity, and actual toxicity of substance suspected of having been ingested

\begin{tabular}{|c|c|c|c|c|c|c|c|c|}
\hline \multirow{3}{*}{ Beliefs of parents on toxicitv } & \multicolumn{6}{|c|}{ True toxicity in acute dosage of substance } & \multirow{2}{*}{\multicolumn{2}{|c|}{ Total }} \\
\hline & \multicolumn{2}{|c|}{ Innocuous } & \multicolumn{2}{|c|}{ Dangerous } & \multicolumn{2}{|c|}{ Toxic } & & \\
\hline & No. & $\%$ & No. & $\%$ & No. & $\%$ & No. & $\%$ \\
\hline $\begin{array}{l}\text { Toxic } \\
\text { Uncertain if toxic }\end{array}$ & $\begin{array}{r}7 \\
19 \\
\end{array}$ & $\begin{array}{l}27 \\
73\end{array}$ & $\begin{array}{l}46 \\
37\end{array}$ & $\begin{array}{l}55 \\
45\end{array}$ & $\begin{array}{l}26 \\
15\end{array}$ & $\begin{array}{l}63 \\
37\end{array}$ & $\begin{array}{l}79 \\
71\end{array}$ & $\begin{array}{l}53 \\
47\end{array}$ \\
\hline Total all parental beliefs & 26 & 100 & 83 & 100 & 41 & 100 & 150 & 100 \\
\hline
\end{tabular}

^In 10 cases patients could not be contacted: in 18 cases parents did not answer questions. 
gestion used by a parent is therefore often indirect, and parental assessment of toxicity of the substance is sometimes not good. The threshold of suspicion is in many cases low. It is also important to remember that the group of children whose parents suspected ingestion of a toxic substance but did not seek medical care have not been studied. We thus have no evidence of the factors which influence the decision not to seek medical care.

Health education. Present health education policy has stressed the dangers to young children of access to certain substances, particularly medicines and drugs. There is no evidence that this has been effective in prevention but, in addition to the natural anxiety a parent has about his child's health, this policy may have created fear among parents and encouraged them to seek medical care on indirect evidence of poisoning. This heightening of parental anxiety may have inflated the problem of childhood poisonings. In future, health education campaigns should be appropriately monitored and evaluated in terms of health costs and benefits, and include the effect on the incidence of true poisoning and on poisoning scares.

Role of the General Practitioner. 32\% of the parents consulted their general practitioners immediately after suspected poisoning had occurred and all but $1 \%$ were referred to hospital. In a follow-up study of the referral policy of general practitioners, 48 of 91 agreed to complete a questionnaire asking how they would advise a parent in situations in which a child was suspected of taking one of six substances of varying toxicity. From the answers it seems that general practitioners refer parents to hospital irrespective of the toxicity of the substances, therefore playing a minor role in treatment, and reinforcing the parent's concern.
Effect of social class. In Table IV the frequency of suspected child poisoning, ranked according to the social class of the male head of household, is compared with the known distribution of social class of males over 15 years of age in the study area. Suspected poisonings occur twice as often in class I households as would be expected. This finding may be attributable to different patterns of use of health services rather than to different accident rates. Previous studies which sampled child poisonings in the general population, and not just in those who use the medical care service, showed no social class difference (Sobel, 1970). Table IV also shows the distribution by social class of true poisoning and poisoning scares again compared with the background population. Children from families of social class I were significantly more likely to be involved in poisoning scares and children from families of social class IV significantly less likely than children from the other classes.*

However, there was no significant association between true poisoning and social class, though the distribution is similar to that of poisoning scares. Establishing the relation between true poisoning and social class requires a larger sample. Alderson (1970) found that middle-class groups tend to use preventive health services more than working-class groups. In many ways the decision to seek medical care in poisoning scare situations resembles the decision to use preventive health services. Fear of potential injury or disease motivates action, rather than response to symptoms. This may explain

\footnotetext{
*In making this calculation from the available census data we assumed that the number of children under 15 years of age resident with the head of household does not vary with social class. In fact, National Child Development Study data (Davie, Butler, and Goldstein, 1972) suggest that the number of children under 21 is less in social class I families. This would further strengthen the hypothesis.
}

Social class of male head of household, economically active or retired, in families involved in suspected poisoning, poisoning scares, or true poisoning in study period compared to that in the 1965 sample census

\begin{tabular}{|c|c|c|c|c|c|c|c|c|c|c|c|c|c|c|c|c|}
\hline \multirow{3}{*}{ Type of poisoning } & \multicolumn{12}{|c|}{ Social class } & \multirow{2}{*}{\multicolumn{2}{|c|}{$-\begin{array}{c}\text { Not } \\
\text { classified }\end{array}$}} & \multirow{2}{*}{\multicolumn{2}{|c|}{$\begin{array}{c}\text { All } \\
\text { cases }\end{array}$}} \\
\hline & \multicolumn{2}{|c|}{ I } & \multicolumn{2}{|c|}{ II } & \multicolumn{2}{|l|}{ III } & \multicolumn{2}{|c|}{ IV } & \multicolumn{2}{|l|}{ V } & \multicolumn{2}{|c|}{$\begin{array}{l}\text { Not } \\
\text { recorded }\end{array}$} & & & & \\
\hline & No. & $\%$ & No. & $\%$ & No. & $\%$ & No. & $\%$ & No. & $\%$ & No. & $\%$ & No. & $\%$ & No. & $\%$ \\
\hline $\begin{array}{l}\text { True poisoning } \\
\text { Poisoning scares } \\
\text { All suspected poisoning } \\
1 \text { in } 10 \text { sample of population study area }\end{array}$ & $\begin{array}{c}5 \\
12 \star \\
17 \star \\
2,39\end{array}$ & $\begin{array}{l}9 \\
11 \\
10 \\
5\end{array}$ & $\begin{array}{r}9 \\
15 \\
24 \\
6,99\end{array}$ & $\begin{array}{l}17 \\
13 \\
14 \\
14\end{array}$ & $\begin{array}{r}25 \\
57 \\
82 \\
23,87\end{array}$ & $\begin{array}{l}46 \\
50 \\
49 \\
66\end{array}$ & $\begin{array}{c}8 \\
9 \dagger \\
17 \dagger \\
8,12\end{array}$ & $\begin{array}{r}15 \\
8 \\
10 \\
16\end{array}$ & $\begin{array}{r}4 \\
7 \\
11 \\
4,12\end{array}$ & $\begin{array}{l}7 \\
6 \\
7 \\
8\end{array}$ & $\begin{array}{l}0 \\
9 \star \\
9 \dagger \\
1,25\end{array}$ & $\begin{array}{l}\mathbf{0} \\
\mathbf{8} \\
\mathbf{5} \\
\mathbf{2}\end{array}$ & $\begin{array}{c}3 \\
5 \\
8+ \\
4,84\end{array}$ & $\begin{array}{l}6 \\
4 \\
5 \\
9\end{array}$ & $\begin{array}{r}54 \\
114 \\
168 \\
51,58\end{array}$ & $\begin{array}{l}100 \\
100 \\
100 \\
100\end{array}$ \\
\hline
\end{tabular}

«Significantly different from expectation $(P \leqslant 0 \cdot 005)$.

+Significantly different from expectation $(P \leqslant 0.05)$

$\neq$ Including female head of household. 
the larger proportion of children in social class I in the group of poisoning scares.

Delay in seeking care. We next examined delays in seeking medical care (Table V). We treated as delayed all cases in which the parent suspected ingestion but waited for 2 hours or more before deciding to seek help. Even when the decision to seek help was made, the parents often sought advice from a 'lay expert', whom they considered to be the legitimate source of help or knowledge in the community. These lay experts were usually nurses, ambulance men, those experienced in bringing up children, or others connected in some way with health service.

Working-class parents were more likely to delay than middle-class parents and, in all cases of delay, waited until a symptomatic 'cue' developed. The findings suggest that working-class parents are more likely to require a different type of evidence before seeking medical attention than middle-class parents. These findings should be compared with reports of the under-utilization of health services by working class groups (Rosenblatt and Suchmann, 1964).

Prevention. Previous workers have suggested the following measures for the prevention of childhood poisoning.

(1) Packaging medicines and drugs in childresistant containers.

(2) Storing medicines and drugs in medicine cupboards.

(3) Reducing the quantity of drugs in the home.

(4) Labelling toxic substances.

Table VI shows true poisoning and poisoning scares by type of substance involved. The most dangerous substances were caustic soda and paraffin. Child-resistant containers, storage cupboards, and labels may need to be considered for these dangerous domestic substances as well as medicines. Over-the-counter medicines were more hazardous to children than prescription drugs. Varieties of

\section{TABLE V}

Proportion of parents delaying for 2 hours or more in seeking care for suspected poisoning, by social class and by presence of symptoms or other signs of distress

\begin{tabular}{|c|c|c|c|c|c|c|c|c|c|c|}
\hline \multirow{3}{*}{ Social class } & \multicolumn{8}{|c|}{ Symptoms or other signs of distress } & \multirow{2}{*}{\multicolumn{2}{|c|}{ Total }} \\
\hline & \multicolumn{4}{|c|}{ Present } & \multicolumn{4}{|c|}{ Absent } & & \\
\hline & No. & $\%$ & No. & $\%$ & No. & $\%$ & No. & $\%$ & No. & $\%$ \\
\hline $\begin{array}{l}\text { Nonmanual } \\
\text { Manual } \\
\text { Not classified } \\
\text { Social class not recorded }\end{array}$ & $\begin{array}{r}2 \\
15 \\
1 \\
-\end{array}$ & $\begin{array}{r}4 \\
16 \\
12 \\
-\end{array}$ & $\begin{array}{r}15 \\
22 \\
2 \\
-\end{array}$ & $\begin{array}{l}30 \\
24 \\
25 \\
-\end{array}$ & $\begin{array}{l}0 \\
0 \\
0 \\
-\end{array}$ & $\begin{array}{r}0 \\
0 \\
0 \\
-\end{array}$ & $\begin{array}{r}33 \\
54 \\
5 \\
-\end{array}$ & $\begin{array}{l}66 \\
59 \\
63 \\
-\end{array}$ & $\begin{array}{r}50 \\
91 \\
8 \\
19\end{array}$ & $\begin{array}{l}100 \\
100 \\
100 \\
-\end{array}$ \\
\hline Total & 18 & 12 & 39 & 26 & 0 & 0 & 92 & 62 & 168 & \\
\hline
\end{tabular}

Note: In the remaining cases information was not available.

TABLE VI

True poisonings and poisoning scares by type of substance suspected of having been ingested

\begin{tabular}{|c|c|c|c|c|c|c|c|c|}
\hline \multirow[b]{2}{*}{$\begin{array}{c}\text { Type of substance suspected of } \\
\text { having been ingested }\end{array}$} & \multicolumn{6}{|c|}{ True poisoning } & \multirow{2}{*}{$\begin{array}{l}\text { Poisoning } \\
\text { scares }\end{array}$} & \multirow[b]{2}{*}{ Total } \\
\hline & Burns & $\begin{array}{l}\text { Collapse } \\
\text { or } \\
\text { coma }\end{array}$ & $\begin{array}{c}\text { Other } \\
\text { signs, e.g. } \\
\text { pneumonia }\end{array}$ & $\begin{array}{l}\text { Vomiting } \\
\text { or } \\
\text { diarrhoea }\end{array}$ & $\begin{array}{c}\text { Drowsi- } \\
\text { ness or } \\
\text { dizziness }\end{array}$ & $\begin{array}{l}\text { Clinical } \\
\text { evidence } \\
\text { only }\end{array}$ & & \\
\hline $\begin{array}{l}\text { Prescribed medicine or drug } \\
\text { Over-the-counter medicines } \\
\text { Household substances } \\
\text { Natural substances } \\
\text { Other }\end{array}$ & $\begin{array}{l}0 \\
4 \\
1 \\
0 \\
0\end{array}$ & $\begin{array}{l}0 \\
0 \\
1 \\
0 \\
0\end{array}$ & $\begin{array}{l}0 \\
1 \\
6 \\
0 \\
0\end{array}$ & $\begin{array}{l}3 \\
5 \\
7 \\
1 \\
2\end{array}$ & $\begin{array}{l}5 \\
2 \\
0 \\
0 \\
0\end{array}$ & $\begin{array}{r}3 \\
19 \\
1 \\
1 \\
0\end{array}$ & $\begin{array}{r}42 \\
24 \\
47 \\
1 \\
2\end{array}$ & $\begin{array}{r}53 \\
55 \\
63 \\
3 \\
4\end{array}$ \\
\hline Total & 5 & 1 & 7 & 18 & 7 & 24 & 116 & 178 \\
\hline
\end{tabular}


junior aspirin accounted for just over half the true poisonings from over-the-counter medicines. Prescribed medicines and drugs appeared proportionally more often in poisoning scares than over-the-counter medicines and household and natural substances, perhaps reflecting the influence of health education campaigns. The introduction of child-resistant containers, particularly strip and blister packs, may reduce the rate of poisoning scares. Clear labelling with advice on storage and information about potential toxicity may help the parent to discriminate better between poisoning scares and true poisoning.

Finally, in $81 \%$ of the cases involving medicines, both prescribed and over-the-counter, the substances had been in use immediately before the accident. Therefore the campaign to reduce unwanted and hoarded medicines and drugs may be relevant to only a small part of the problem.

\section{Conclusions and proposals}

In a community study in North East Bristol covering 53000 person-years-at-risk of children aged under 15 years, we found 183 cases of supected poisoning in which medical care services were used. From these cases we estimate case incidence in that area to be $3 \cdot 45 / 1000$ children aged under 15 per year and also estimate that 40000 such cases a year occur in the U.K.

Detailed evidence from home visits and from hospital records shows that in at least $65 \%$ and possibly as many as $78 \%$ of these cases there was no evidence of poisoning. Previous studies and statistics have not distinguished true poisoning from poisoning scares. This may have exaggerated the concern for the problem and encouraged a less-thanprudent attitude to the risk of false postive cases. Staff in medical care services should be more aware of false positives and the need to examine carefully the balance of probabilities in each case by careful history taking and clinical assessment. In future programmes of health education the cost and degree of success in reducing true poisoning should be determined and weighed against the likelihood of increasing poisoning scares and their not inconsiderable costs. Suspected poisoning occurs more often among children from families of social class I than among children from other social classes. This finding may result from different patterns of use of health services rather than from different accident rates.

Future health education programmes should emphasize care with household substances such as paraffin and caustic soda, and with over-the-counter medicines, especially junior aspirins. The need to be careful with drugs and dangerous household substances should be stressed rather than emphasizing the disposal of old drugs.

We acknowledge the contribution of all members of the Medical Research Division, especially Dr. J. L. Roberts, who co-ordinated the Home Accident Research programme, and Dr. W. T. Jones. We also thank the Director General, Mr. A. C. L. Mackie, and the Health Education Council for their support.

\section{REFERENCES}

Alderson, M. R. (1970). Social class and the health services. Medical Officer, 124, 50.

Carter, A. P., and Wilkinson, A. (1966). Pilot survey of poisoning in children. Medical Officer, 115, 319.

Davie, R., Butler, N., and Goldstein, H. (1972). From Birth to Seven, p. 228. Longmans, London.

de Fonseka, C. P., and Roberts, J. L., (1972). Investigating accidents in the home. Bristol Medical Chirurgical fournal, 87, 37.

Goulding, R. (1971). Self-poisoning. British fournal of Hospital Medicine, 5, 249.

Jackson, R. H., Walker, J. H., and Wynne, N. A. (1968). Circumstances of accidental poisoning in childhood. British Medical Fournal, 4, 245.

Meadow, S. R., and Smithells, R. W. (1971). Emptying the stomach. (Letter.) British Fournal of Hospital Medicine, 6, 233.

McKendrick, T. (1960). Poisoning accidents in childhood. Archives of Disease in Childhood, 35, 127.

Rosenblatt, D., and Suchmann, E. A. (1964). The under-utlization of the medical care services by blue-collarities. Blue-Collar World. Ed. by A. Shostak and W. Gomberg. Prentice Hall, New York.

Sobel, R. (1970). Psychiatric implications of accidental poisoning in childhood. Pediatric Clinics of North America, 17, 653.

Correspondence to Dr. J. W. Dale, South East Thames Regional Health Authority, Randolph House, 46-48 Wellesley Rd., Croydon CR9 3QA. 